\title{
Cost-Effectiveness of a Proteomic Test for Preterm Birth Prediction
}

\author{
Michael Grabner (1D \\ Julja Burchard (D) ${ }^{2}$ \\ Chi Nguyen (D) ${ }^{3}$ \\ Haechung Chung (iD ${ }^{4}$ \\ Nilesh Gangan (iD) ${ }^{3}$ \\ J Jay Boniface $\mathbb{D}^{2}$ \\ John AF Zupancic (D) ${ }^{5}$ \\ Eric Stanek \\ 'Scientific Affairs, HealthCore, Inc., \\ Wilmington, DE, USA; ${ }^{2}$ Research and \\ Development, Sera Prognostics, Salt Lake \\ City, UT, USA; ${ }^{3}$ Health Economics and \\ Outcomes Research, HealthCore, Inc., \\ Wilmington, DE, USA; ${ }^{4}$ Research \\ Operations, HealthCore, Inc., \\ Wilmington, DE, USA; ${ }^{5}$ Department of \\ Neonatology, Beth Israel Deaconess \\ Medical Center, Harvard Medical School, \\ Boston, MA, USA
}

Correspondence: Michael Grabner Scientific Affairs, HealthCore, Inc., 123 Justison St, Suite 200, Wilmington, DE, 1980I, USA

Tel +I 302-230-2000

Email mgrabner@healthcore.com
Background: Preterm birth (PTB) carries increased risk of short- and long-term health problems as well as higher healthcare costs. Current strategies using clinically accepted maternal risk factors (prior PTB, short cervix) can only identify a minority of singleton PTBs.

Objective: We modeled the cost-effectiveness of a risk-screening-and-treat strategy versus usual care for commercially insured pregnant US women without clinically accepted PTB risk factors. The risk-screening-and-treat strategy included use of a novel PTB prognostic blood test $\left(\right.$ PreTRM $\left.^{\mathbb{R}}\right)$ in the 19th-20th week of pregnancy, followed by treatment with a combined regimen of multi-component high-intensity-case-management and pharmacologic interventions for the remainder of the pregnancy for women assessed as higher-risk by the test, and usual care in women without higher risk.

Methods: We built a cost-effectiveness model using a combined decision-tree/Markov approach and a US payer perspective. We modeled 1-week cycles of pregnancy from week 19 to birth (preterm or term) and assessed costs throughout the pregnancy, and further to 12 months post-delivery in mothers and 30 -months in infants. PTB rates and costs were based on $>40,000$ mothers and infants from the HealthCore Integrated Research Database ${ }^{\circledR}$ with birth events in 2016. Estimates of test performance, treatment effectiveness, and other model inputs were derived from published literature.

Results: In the base case, the risk-screening-and-treat strategy dominated usual care with an estimated 870 fewer PTBs (20\% reduction) and \$54 million less in total cost (\$863 net savings per pregnant woman). Reductions were projected for neonatal intensive care admissions $(10 \%)$, overall length-of-stay $(7 \%)$, and births $<32$ weeks $(33 \%)$. Treatment effectiveness had the strongest influence on cost-effectiveness estimates. The risk-screening-and-treat strategy remained dominant in the majority of probabilistic sensitivity analysis simulations and model scenarios.

Conclusion: Use of a novel prognostic test during pregnancy to identify women at risk of PTB combined with evidence-based treatment is estimated to reduce total costs while preventing PTBs and their consequences.

Keywords: preterm birth, cost effectiveness, progesterone, prognostic test

\section{Plain Language Summary}

- In the US, over $10 \%$ of infants are born prematurely (before 37 weeks' gestation).

- Preterm birth (PTB) carries increased risk of short- and long-term health problems for infants, and higher healthcare costs for mothers and infants.

- Current strategies using clinically accepted maternal risk factors (prior PTB, short cervix) can only identify a minority of singleton PTBs.

- We created a decision-analytic model to compare a risk-screening-and-treat strategy to usual care in women at low risk of PTB by clinically accepted risk factors; the new 
strategy consisted of a novel blood test $\left(\right.$ PreTRM $\left.^{\mathbb{R}}\right)$ that is prognostic for PTB when applied in the 19th-20th week of pregnancy, followed by treatment among women assessed as higher-risk by the test with modelling of effect sizes derived from the literature on multi-component high-intensity case management and pharmacologic interventions.

- The cost-effectiveness evaluation demonstrated that this strategy of screening otherwise low-risk pregnant women and treating those identified as higher-risk could lower total healthcare costs and prevent preterm births.

- Sensitivity analyses confirmed robustness of the model and showed the importance of treatment effectiveness in assessing whether the risk-screening-and-treat strategy would be cost-saving.

\section{Introduction}

Preterm birth (PTB) carries increased risk of short- and longterm health problems for infants, and higher healthcare costs for mothers and infants. ${ }^{1-3}$ In the US, about $10 \%$ of infants are born prematurely (before 37 weeks' gestation). ${ }^{4}$ The economic burden of PTB has been estimated at \$25 billion annually, much of which is the direct cost of medical care in infancy., Within the category of PTB, risk of the most serious sequelae and highest cost is not uniformly distributed, but much greater for delivery at earlier weeks of gestational age. ${ }^{7,8}$ Each additional week in utero means better outcomes, including avoidance of major neonatal morbidity and death. ${ }^{8}$

PTB is classified into subtypes of spontaneous PTB (spontaneous onset of labor or following preterm premature rupture of membranes; $\mathrm{SPTB}$ ) and medically indicated PTB (miPTB). PTB can follow preterm labor - often idiopathic or related to occult intraamniotic infection, polyhydramnios, uterine fibroids, and other predisposing or initiating conditions. Typical medical indications include preeclampsia, placental abruption, intrauterine growth restriction, and fetal distress; in some cases, these conditions may also predispose to spontaneous onset of labor. ${ }^{9}$

Although addressing the risk of prematurity has been a national priority for decades, progress has been challenged by many PTBs being spontaneous, without evident clinically accepted maternal risk factors or fetal abnormalities, and its heterogeneous and multifactorial nature. ${ }^{10}$ Reducing neonatal morbidity, mortality, and costs requires identifying at-risk women sufficiently early to effectively intervene. The shortcomings of clinically accepted maternal risk factors (prior PTB, short cervix) which only identify a minority of singleton PTBs, ${ }^{11-13}$ has led to interest in the use of biomarker approaches for the identification of otherwise at-risk women. A test to predict a majority of preterm deliveries is optimally constructed with biomarkers that address general pathways downstream from multiple PTB etiologies.

We evaluated the cost-effectiveness of a risk-screening-and-treat strategy, compared to usual care, for a population of commercially insured pregnant women in the US without clinically accepted risk factors for PTB as of the 19th-20th week of pregnancy. The approach included one-time screening with a proteomic blood test $\left(\right.$ PreTRM $^{\circledR}$, Sera Prognostics), which has demonstrated in the 19th-20th week of pregnancy clinically valid prediction of risk of sPTB $<37$ weeks and enrichment by its biomarkers of early PTB (both spontaneous and medically indicated) and adverse neonatal outcomes. ${ }^{14,15}$ In our model, women identified as higher-risk via this test would then be offered established PTB prevention measures, such as high-intensity case management (HICM) and/or pharmacologic interventions. ${ }^{16-18}$

One previous study evaluated the potential clinical and cost outcomes of adopting a hypothetical test similar to PreTRM using national data and found that if all pregnant women in the US received the test, approximately 23,000 PTBs would have been prevented with savings of approximately $\$ 500$ million in the first year of infant life. ${ }^{19}$ Our study was designed to provide a complementary perspective using real-world data from a large US commercial health plan, and to refine specific features of the previous analysis. In particular, our objective was to develop a detailed decision-analytic model to estimate the medium-term cost-effectiveness of the PreTRM test compared to usual care.

\section{Methods}

We conducted a cost-effectiveness analysis using published literature and observational data from administrative claims. Economic modelling best practices were followed. ${ }^{20}$ Researchers' access to claims data was limited to data stripped of identifiers to ensure confidentiality. HealthCore maintains data use agreements with the covered entities in compliance with the Health Insurance Portability and Accountability Act. An Institutional Review Board did not review the study since only this limited data set was accessed.

\section{Data Sources}

The study population was based on a cohort of commercially insured pregnant women age $\geq 18$ with singleton 
pregnancy, and a separate cohort of live-born singleton infants, based on birth events between January 1 and December 31, 2016. Data were extracted from the HealthCore Integrated Research Database $\left(\operatorname{HIRD}^{\circledR}\right)$, a repository of fully adjudicated, longitudinal claims from a large national commercial payer with membership in all 50 US states. Inclusion/exclusion criteria (Appendix Table A1) were further applied to ensure sufficient medical and pharmacy enrollment coverage and to select women corresponding to the test's low-risk intended-use population; for example, women on progesterone in weeks 13 through 20 of gestation were excluded as this would be common routine care for women with prior PTB and/or short cervical length. Pregnancy, birth, neonatal outcome, and direct healthcare cost data were generated from the HIRD in weekly epochs of gestational age spanning from $<23$ weeks to $\geq 37$ weeks (term).

Assumptions on test uptake and performance as well as treatment initiation and adherence were derived from published literature and expert opinion. Estimates of treatment effectiveness were based on published data examining the impact of different versions of HICM, progesterone, and bundles of these modalities on PTBs (a detailed derivation of the effectiveness estimates is provided in the Appendix). ${ }^{17,19,21-27}$ In our model, the treatment arm specifically included HICM consisting of up to two additional visits to a maternal-fetal medicine specialist, up to two additional transvaginal ultrasounds, and up to 10 additional nursing calls; daily low-dose $(81 \mathrm{mg})$ aspirin; and vaginal progesterone $200 \mathrm{mg} /$ day; all from weeks 22 up through $36 .{ }^{26-29}$ The model assumes similar treatment effectiveness in women determined to be higherrisk by the PreTRM test as that observed for women determined to be high-risk by clinically accepted identification approaches (such as short cervix and prior preterm birth).

Key parameters of the model are described in Table 1 with their base case values, ranges for sensitivity analysis, and sources.

\section{Decision-Analytic Model}

We created a decision-analytic model from the perspective of a US commercial health plan, using TreeAge Pro and Microsoft Excel. The model examined two strategies, usual care vs one-time testing via PreTRM followed by a therapeutic approach comprising multi-component HICM and pharmacological interventions in pregnant women found to be at high risk of preterm birth (riskscreening-and-treat arm). Usual care could include lowfrequency use of progesterone, aspirin, or other treatments; our study did not further quantify routine practice patterns in this low-risk population but took these patterns and their associated PTB frequencies and cost outcomes as given. These women without clinically accepted risk factors would not have been subject to guidelines that generate particular routine interventions in current practice.

The model starts with a choice of usual care or riskscreening-and-treat at the 19th week of pregnancy. In the risk-screening-and-treat arm, chance nodes (governed by the probabilities listed in Table 1) determine whether the screening is actually performed, what the results are, whether the therapeutic treatment is initiated, and how adherent patients are to the treatment (Appendix Figure A1). At the end of each branch, identical Markov models advance in 1-week cycles until all pregnancies result in either a PTB or term birth ( $\geq 37$ weeks) (Appendix Figure A2). We assumed the effect of the treatment began at week 23 to allow a 4-week time lag from the decision to test, including conducting the test and reporting results, to initiation of preventive measures and their earliest possible impact on PTB risk Therefore, PTBs in weeks 19-22 are the same in both arms. Transition probabilities determine the chance of maintaining pregnancy to each subsequent week. Separate transition probabilities were derived for each arm. For usual care, the observed number of pregnancies and PTBs from the HIRD were used to calculate PTB risks. For the risk-screening-and-treat arm, the HIRD PTB risks were modified by the estimated weekly treatment effects, modelled as relative risk ratios, derived from previous literature on multi-component regimens (Appendix Table A2).

\section{Cost and Effectiveness Outcomes}

The model tracked direct healthcare costs (paid amounts as recorded in medical and pharmacy claims, aggregated across payer and patient components) over the medium term, defined as, for mothers, from beginning of pregnancy to 1 year post-delivery, and for infants from birth up to 30 months of life or disenrollment (to account for neonatal and early childhood developmental issues associated with PTB). All costs were adjusted to 2018 US dollars based on the Consumer Price Index for health care ${ }^{30}$ Healthcare costs attributable to mothers included prenatal care costs (eg, ultrasounds, testing, treatments), delivery hospitalization costs, and post-natal costs, across all places of service. All-cause costs across all places of service, including neonatal care costs, were used for infants. Costs for progesterone and HICM were taken from public sources. 
Table I Model Inputs

\begin{tabular}{|c|c|c|c|}
\hline & $\begin{array}{l}\text { Base Case } \\
\quad \text { Value }\end{array}$ & $\begin{array}{l}\text { Range } \\
\text { (Lower- } \\
\text { Upper) }\end{array}$ & Source \\
\hline Number of live births (Jan-Dec 2016) & 62,093 & NA & HIRD \\
\hline $\begin{array}{l}\text { Number }(\%) \text { of preterm births under usual } \\
\text { care }\end{array}$ & $4360(7.0 \%)$ & NA & HIRD \\
\hline Proportion of women opting to be tested & 0.85 & $0.70-1.00$ & Expert opinion \\
\hline $\begin{array}{l}\text { Characteristics of PreTRM }{ }^{\circledR} \text { test } \\
\text { Sensitivity* } \\
\text { Specificity* } \\
\text { Cost (one-time) }\end{array}$ & $\begin{array}{l}0.75 \\
0.74 \\
\$ 745\end{array}$ & $\begin{array}{c}0.5-0.83 \\
0.49-0.82 \\
\$ 395-1000\end{array}$ & $\begin{array}{l}\text { Saade } 2016^{14} \text {; data on file } \\
\text { Saade } 2016^{14} \text {; data on file } \\
\quad \text { Expert opinion }\end{array}$ \\
\hline $\begin{array}{l}\text { Proportion of women identified as high-risk } \\
\text { opting to receive treatment }\end{array}$ & 0.90 & $0.60-1.00$ & Expert opinion \\
\hline \multicolumn{4}{|c|}{ Characteristics of treatment for high-risk pregnancies } \\
\hline $\begin{array}{l}\text { Proportion of treated women who adhere to the } \\
\text { treatment }\end{array}$ & 0.80 & $0.60-1.00$ & Expert opinion \\
\hline $\begin{array}{l}\text { Cost of high-intensity case management, including } \\
\text { additional MFM specialist visits, weekly nurse } \\
\text { monitoring, additional ultrasounds for cervical length } \\
\text { assessment, and daily low-dose aspirin (per week) }\end{array}$ & $\$ 54.2$ & $\$ 34.2-58.2$ & $\begin{array}{l}\text { CMS physician fee schedule for office visits and } \\
\text { transvaginal ultrasounds (2019), plus generic cost of } \\
\text { low-dose aspirin }\end{array}$ \\
\hline Cost of progesterone (per week) & $\$ 26$ & $\$ 20-50$ & $\begin{array}{l}\text { Average wholesale price for } 200 \mathrm{mg} / \text { day. Lower bound } \\
\text { represents generic oral progesterone.** Upper bound } \\
\text { based on average of branded oral and vaginal } \\
\text { formulations }\end{array}$ \\
\hline $\begin{array}{l}\text { Effectiveness of treatment (risk ratio for preterm } \\
\text { birth reduction) }\end{array}$ & $\begin{array}{l}0.13-0.68 \text {; } \\
\text { depending on } \\
\text { gestational } \\
\text { week }\end{array}$ & $\begin{array}{l}\text { 0.0I-0.83; } \\
\text { depending on } \\
\text { gestational } \\
\text { week }\end{array}$ & $\begin{array}{c}\text { Analysis of published literature on multi-component } \\
\text { regimens (see Appendix Table A2 and "Methods } \\
\text { Comments" section for details) }\end{array}$ \\
\hline
\end{tabular}

Notes: Usual care assumes no testing and minimal progesterone use. $*$ Sensitivity and specificity are linked via the following equation: Specificity $=2.0062+2.4210 \times$ In (I-Sensitivity) $-2.6145 \times$ Sensitivity $+7.2006 \times$ Sensitivity $^{2}$. **Based on expert opinion, we assumed the majority of vaginal progesterone use is via suppository or direct insertion of an oral progesterone formulation.

Abbreviations: CMS, Center for Medicare and Medicaid Services; HIRD, HealthCore Integrated Research Database; MFM, maternal-fetal medicine.

The primary effectiveness metric was the number of PTBs (births $<37$ weeks). The usual care arm distribution of PTBs (including both spontaneous and medically indicated) was identified from the neonates' claims around the birth date using International Classification of Diseases, Tenth Revision, Clinical Modification (ICD-10-CM) codes (see Appendix "Methods Comments"). Other effectiveness outcomes included number of PTBs at $<32$ and $<35$ weeks, neonatal intensive care unit (NICU) admission, infant length of stay during delivery hospitalization (overall and in NICU), and neonatal morbidity/mortality index (NMI) changes. The NMI, a composite event score used in a multicenter trial of vaginal progesterone, ${ }^{31}$ was adapted to be estimated from claims (see Appendix "Methods Comments").

Cost-effectiveness was assessed via the incremental cost-effectiveness ratio (ICER), expressed as the costs of adopting the risk-screening-and-test strategy minus costs for usual care, divided by the difference in total PTBs. Health outcomes and costs were not discounted given the short time horizon of the analysis.

\section{Sensitivity Analysis}

One-way and probabilistic sensitivity analyses (PSA) as well as scenario analyses were conducted to evaluate outcomes under variations in model parameters and to 
quantify the effects of uncertainty. Results from the oneway sensitivity analysis (using ranges described in Table 1 and Appendix Table A3) are presented as tornado plots. PSA used a Monte Carlo approach based on 10,000 randomly generated simulations of parameter values; results are presented as ICER scatter plots on the cost-effectiveness plane. Scenario analyses were conducted for key parameters not considered in the one-way and probabilistic sensitivity analyses such as treatment effectiveness (see Table 2 for details).

\section{Results}

\section{Description of Study Cohort}

We identified 62,093 live births in calendar year 2016 without claims indicating multiple gestation, and with at least one available indicator of gestational age (assessed on or within 30 days of birth). These 62,093 infants served as the basis of the model. Pregnant women aged $\geq 18$, giving birth in an inpatient setting in 2016, were identified separately and included if they had no evidence of multiple gestation, early progesterone therapy (12-21 weeks of gestation), fetal abnormalities, preterm labor $<21$ weeks, or claims for stillbirth or abortion. Approximately twothirds of women and infants were continuously enrolled in the health plan during the pregnancy and for at least 12 months after the birthdate. Mean (SD) age of mothers was 30.2 (5.1) years at the time of delivery. Women resided in all regions of the US, predominantly in the South (33\%) and Midwest (28\%). Sixty-eight percent of infants were delivered vaginally, and $52 \%$ were male.

The overall PTB frequency using infant claims was $7.0 \%$ in this selected population, which was used as the

Table 2 Model Results: Base Case and Scenario Analyses

\begin{tabular}{|c|c|c|c|c|c|}
\hline & $\begin{array}{l}\text { Usual } \\
\text { Care }\end{array}$ & $\begin{array}{l}\text { Risk-Screening- } \\
\text { and-Treat } \\
\text { Strategy }\end{array}$ & $\begin{array}{c}\text { Incremental } \\
\text { Difference }\end{array}$ & $\begin{array}{l}\text { Savings per } \\
\text { Prevented } \\
\text { PTB* }\end{array}$ & $\begin{array}{l}\text { Savings per } \\
\text { Pregnant } \\
\text { Woman }\end{array}$ \\
\hline Base case & & & & \multirow{3}{*}{$\$ 6 I, 58 I$} & \multirow{3}{*}{$\$ 863$} \\
\hline Cost (USD) & $\$ 261 \mathrm{Im}$ & $\$ 2558 \mathrm{~m}$ & $-\$ 53.6 \mathrm{~m}$ & & \\
\hline Number of preterm births & 4360 & 3490 & -870 & & \\
\hline $\begin{array}{l}\text { Scenario I: Lower treatment effectiveness } \\
\text { Cost (USD) }\end{array}$ & $\$ 261 \mathrm{Im}$ & $\$ 2613 \mathrm{~m}$ & $\$ 1.7 \mathrm{~m}$ & \multirow[t]{2}{*}{$\$ 3989$ (ICER) } & \multirow[t]{2}{*}{ N/A } \\
\hline Number of preterm births & 4360 & 3924 & -436 & & \\
\hline $\begin{array}{l}\text { Scenario 2: Higher treatment effectiveness } \\
\text { Cost (USD) }\end{array}$ & $\$ 261 \mathrm{Im}$ & $\$ 2518 \mathrm{~m}$ & $-\$ 93.6 \mathrm{~m}$ & \multirow{2}{*}{$\$ 70,722$} & \multirow{2}{*}{$\$ 1508$} \\
\hline Number of preterm births & 4360 & 3036 & -1324 & & \\
\hline $\begin{array}{l}\text { Scenario 3: Alternate infant cost definition } \\
\text { Cost (USD) }\end{array}$ & $\$ 2876 \mathrm{~m}$ & $\$ 2803 \mathrm{~m}$ & $-\$ 73.4 \mathrm{~m}$ & \multirow[t]{2}{*}{$\$ 84,344$} & \multirow[t]{2}{*}{$\$ 1182$} \\
\hline Number of preterm births & 4360 & 3490 & -870 & & \\
\hline $\begin{array}{l}\text { Scenario 4: Infant costs } 0-12 \text { months only } \\
\text { Cost (USD) }\end{array}$ & $\$ 2438 \mathrm{~m}$ & $\$ 2387 \mathrm{~m}$ & $-\$ 5 I .1 \mathrm{~m}$ & \multirow[t]{2}{*}{$\$ 58,727$} & \multirow[t]{2}{*}{$\$ 823$} \\
\hline Number of preterm births & 4360 & 3490 & -870 & & \\
\hline $\begin{array}{l}\text { Scenario 5: Infant costs } 0-12 \text { months only, } \\
\text { with alternate infant cost definition } \\
\text { Cost (USD) }\end{array}$ & $\$ 2548 \mathrm{~m}$ & $\$ 2481 \mathrm{~m}$ & $-\$ 67.7 \mathrm{~m}$ & \multirow[t]{2}{*}{$\$ 77,779$} & \multirow[t]{2}{*}{$\$ 1090$} \\
\hline Number of preterm births & 4360 & 3490 & -870 & & \\
\hline
\end{tabular}

Notes: In Scenario I, where incremental costs are positive, there are no savings and the number presented equals the actual ICER. Costs presented in 2018 USD. Incremental costs = risk-screening-and-treat strategy costs minus usual care costs. Risk-screening-and-treat is dominant (cost-saving and at least I preterm birth prevented) in the base case and all scenarios except Scenario I. See Appendix for definitions of lower (Scenario I) and higher (Scenario 2) treatment effectiveness. In Scenario 3, only costs from infants who were fully enrolled in their health plan over the 30-month follow-up time period were utilized (vs also using costs of those with <30-months enrollment; see Appendix Table A4). Scenario 4 truncated the modelling timeframe to the first 12 months after birth to observe a shorter-term impact (vs using 30 months). Scenario 5 used fully enrolled I2-month infant costs and a 12-month modelling horizon (a combination of Scenarios 3 and 4 ). *Equal to the absolute value of the ICER. Abbreviations: PTB, preterm birth; m, million. 
usual care rate for the economic analysis. As expected, costs by gestational age were higher on a per-patient basis for all preterm weeks (Figure 1 and Appendix Table A3). Births $<32$ weeks had the highest costs compared to term births, close to $\$ 400,000$ on average for the year following birth. Maternal costs were more consistent across gestational ages than infant costs but still showed a relationship, with PTBs in weeks $23-36$ averaging from $30 \%$ higher to more than double the cost of full-term births for the mother (\$24,143 for week 37 and beyond).

\section{Base Case Analysis}

Using base case inputs of test uptake and performance, 15,570 mothers (out of 62,093) were identified as high-risk by the PreTRM test, with 11,210 receiving the treatment and remaining adherent. Under base case treatment effectiveness assumptions (see Appendix for details), 870 preterm births $(20 \%$ of all preterm births in the cohort) were prevented in the risk-screening-and-test arm (Table 2). Incremental costs of the risk-screening-and-treat strategy in weeks leading up to delivery (\$56 million) were more than offset by the reduction in costs of prevented PTBs (\$109 million). Total costs for women (antenatal and 12months postnatal) and infants (first 30-months) were therefore reduced by $\$ 54$ million, an average net cost savings of $\$ 863$ per pregnant woman, or $\$ 61,581$ per prevented PTB. Risk-screening-and-treat is therefore a dominant strategy (improved outcomes at lower cost vs usual care) and no ICER was calculated. Fewer infants were born very early (33\% reduction in gestational age $<32$ weeks; $26 \%$ reduction in $<35$ weeks) and fewer required admission to the NICU (9.8\% reduction in NICU admissions). Length of hospital stay for infants was reduced by $7 \%$ overall and by $20 \%$ for NICU stays, and the proportion of infants with an NMI score $\geq 3$, indicating severe morbidity or mortality, decreased by $23 \%$ (Table 3, Appendix Figure A3).

\section{Sensitivity Analyses}

Sensitivity analyses indicated that only the estimated effectiveness of the multi-component prevention regimen strongly influenced cost-effectiveness estimates (Figure 2A). Assuming lower effectiveness negated the cost savings

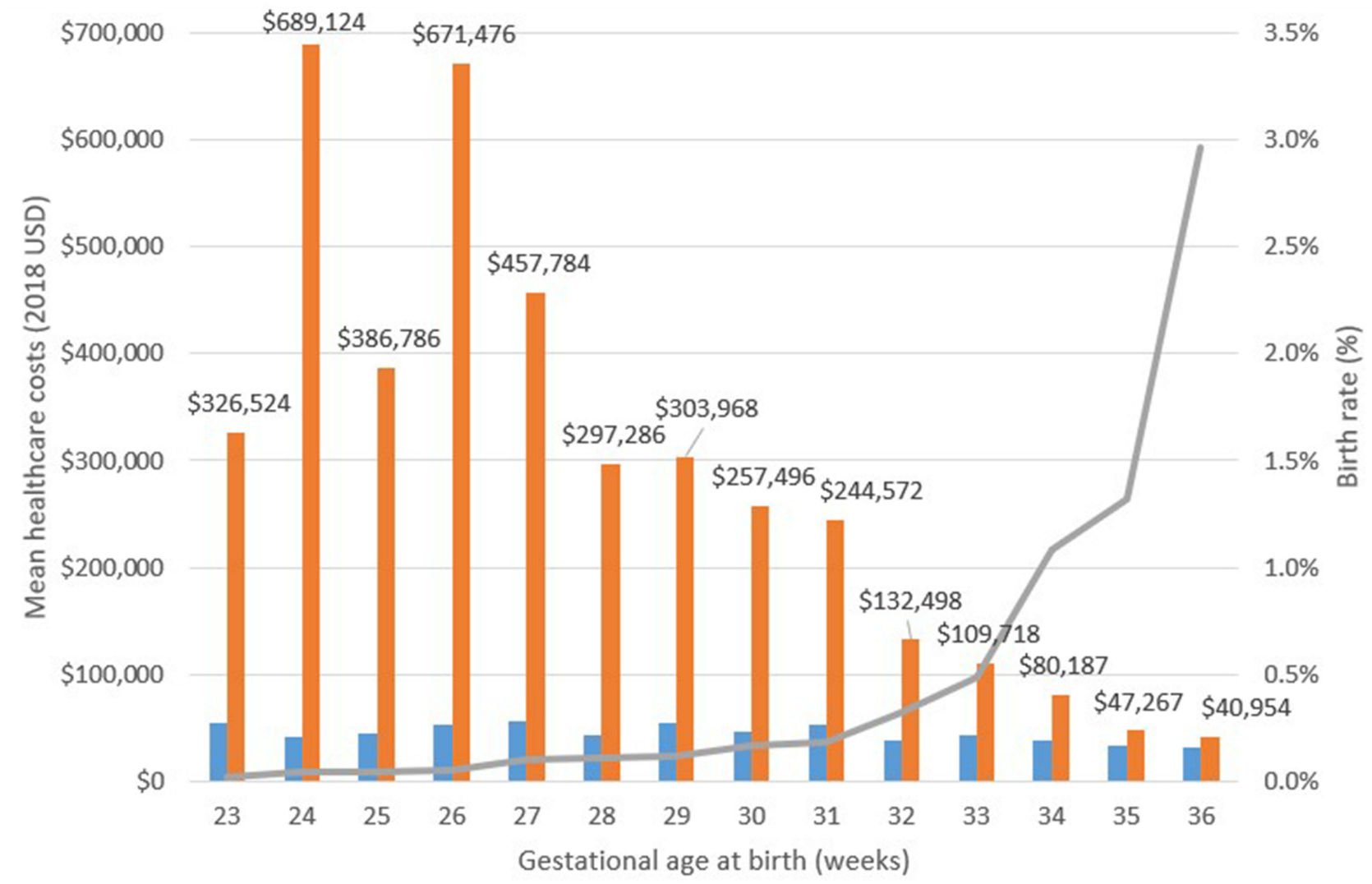

Maternal costs Infant costs $=$ Birth rate

Figure I Health care costs for the first year of life and preterm birth rates by gestational age, usual care, 2016 data from the HealthCore Integrated Research Database. 
Table 3 Model Results: Base Case Additional Endpoints

\begin{tabular}{|c|c|c|c|}
\hline Outcome & Usual Care & $\begin{array}{c}\text { Risk-Screening-and- } \\
\text { Treat Strategy }\end{array}$ & $\begin{array}{c}\text { Incremental } \\
\text { Difference (\%) }\end{array}$ \\
\hline Total cost (USD) for births $<37$ weeks & $\$ 566 \mathrm{~m}$ & $\$ 426 m$ & $-\$ 140 m(-24.8 \%)$ \\
\hline $\begin{array}{l}\text { Number of PTBs (\% relative to total population) } \\
<32 \text { weeks' gestational age } \\
<35 \text { weeks' gestational age } \\
<37 \text { weeks' gestational age (total) }\end{array}$ & $\begin{array}{l}525(0.85 \%) \\
1698(2.73 \%) \\
4360(7.02 \%)\end{array}$ & $\begin{array}{c}35 \mathrm{I}(0.57 \%) \\
1250(2.01 \%) \\
3490(5.62 \%)\end{array}$ & $\begin{array}{l}-174(-33.1 \%) \\
-448(-26.4 \%) \\
-870(-20.0 \%)\end{array}$ \\
\hline $\begin{array}{l}\text { Infant outcomes for births }<37 \text { weeks } \\
\text { Any NICU admission (\% relative to total population) } \\
\text { Length of stay (days) } \\
\text { NICU length of stay (days) } \\
\text { Mean neonatal morbidity/mortality index over } 30 \text { days from birth } \\
\text { Neonatal morbidity/mortality index } \geq 3 \text { (\% relative to total } \\
\text { population) }\end{array}$ & $\begin{array}{c}2821(4.54 \%) \\
17.83 \\
16.52 \\
1.32 \\
870(1.40 \%)\end{array}$ & $\begin{array}{c}2194(3.53 \%) \\
16.37 \\
15.00 \\
1.26 \\
632(1.02 \%)\end{array}$ & $\begin{array}{l}-628(-22.2 \%) \\
-1.46(-8.2 \%) \\
-1.52(-9.2 \%) \\
-0.06(-4.5 \%) \\
-238(-27.4 \%)\end{array}$ \\
\hline $\begin{array}{l}\text { Infant outcomes for all births } \\
\text { Any NICU admission (\% relative to total population) } \\
\text { Length of stay (days) } \\
\text { NICU length of stay (days) } \\
\text { Mean neonatal morbidity/mortality index over } 30 \text { days from birth } \\
\text { Neonatal morbidity/mortality index } \geq 3 \text { (\% relative to total } \\
\text { population) }\end{array}$ & $\begin{array}{c}5939(9.56 \%) \\
4.04 \\
1.53 \\
0.19 \\
1037(1.67 \%)\end{array}$ & $\begin{array}{c}5358(8.63 \%) \\
3.75 \\
1.22 \\
0.16 \\
801 \text { ( } 1.29 \%)\end{array}$ & $\begin{array}{l}-581(-9.8 \%) \\
-0.29(-7.2 \%) \\
-0.31(-20.3 \%) \\
-0.02(-11.0 \%) \\
-236(-22.7 \%)\end{array}$ \\
\hline
\end{tabular}

Notes: Costs presented in 2018 US dollars (USD). Percentages are relative to the total population of 62,093.

Abbreviations: NICU, neonatal intensive care unit; PTB, preterm birth; m, million.

gained in the base case. Nevertheless, cost per PTB prevented in this case $(\$ 3989$; Table 2$)$ remained favorable for decision-makers with a willingness-to-pay threshold of $\geq \$ 4000$ per prevented PTB. When varying the cost, sensitivity, and specificity of the PreTRM test, eg, to account for any differences in the PTB risk of this commercially insured population vs the population used for the test validation, the risk-screening-and-treat strategy remained cost saving. Using PTB $<32$ or $<35$ as the endpoint, the risk-screeningand-treat strategy also remained cost saving in univariate sensitivity analysis (see Appendix Figures A4 and A5 for the ranking of influential parameters).

Scenario analysis tested changes to key parameters (higher/lower treatment effectiveness, alternative infant cost definition, use of a 12-month time horizon for infant costs) and found that the risk-screening-and-treat strategy remained dominant, resulting in both cost savings and avoided preterm births (Table 2). The only exception was in Scenario 1, which assumed lower treatment effectiveness, mirroring the oneway sensitivity analysis finding for this same variable.

The risk-screening-and-treat strategy was cost-saving in all base-case PSA simulations (Figure 2B). Since the base case one-way sensitivity analysis and Scenario 1 had identified low treatment effectiveness as potentially negating cost savings, we performed a separate PSA in Scenario 1 (where treatment effectiveness was set to "low"). Under this assumption, the risk-screening-and-treat strategy remained dominant (cost saving) in $32 \%$ of the 10,000 simulations, and was $>80 \%$ likely to be cost-effective with a willingness to pay of $\geq \$ 30,000$ per prevented PTB (Appendix Figure A6).

\section{Discussion}

Reducing PTBs is a leading goal of national health policy in the US. ${ }^{32}$ Women with a low-risk profile based on currently available information nonetheless carry considerable PTB burden, reflecting the need for better prognostic approaches. This study is the first economic evaluation of which we are aware using real-world data to assess the potential value of the PreTRM test for PTB risk in a commercially insured US population. Results suggest that the combination of this test with evidence-based multi-component prevention regimens in otherwise low-risk pregnant women provides a substantial reduction in PTBs while reducing overall health care spending. Fewer PTBs also translate into fewer sequelae for the newborns, which in our study can be seen in the lower rates 

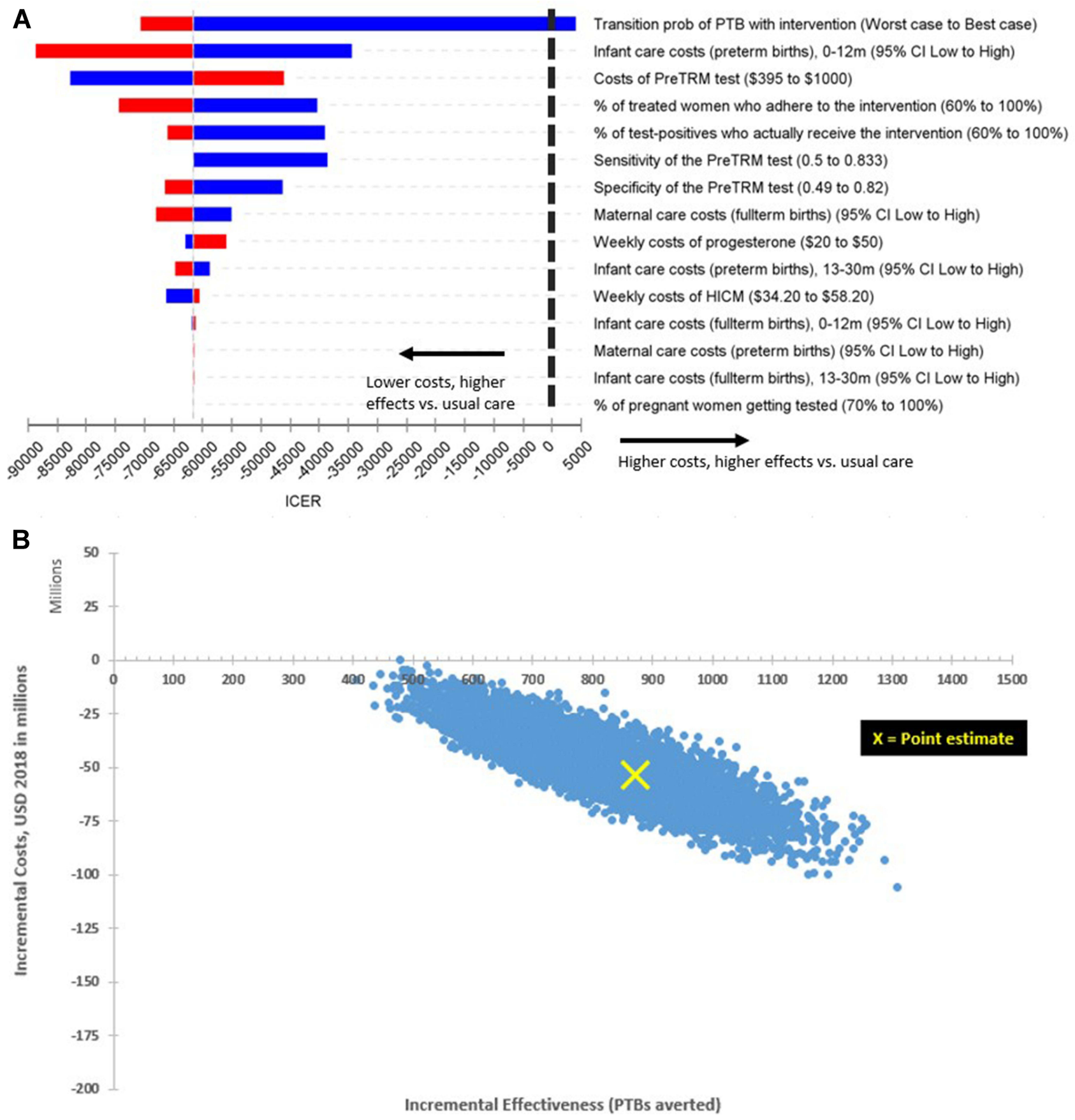

Figure 2 Model results: Sensitivity analyses. (A) Univariate sensitivity analysis (tornado diagram), base case. The tornado diagram (upper panel) ranks input parameters by their influence on the incremental cost-effectiveness ratio (ICER), from highest to lowest. (B) Probabilistic sensitivity analysis, base case. Each blue dot in the ICER scatter plot (lower panel) represents one of the 10,000 PSA simulation outcomes. The scatter plot is wedge-shaped with all mass in the second quadrant. All dots below the x-axis represent cost savings. In the base case, all simulations are associated with cost savings and PTB reductions.

Abbreviations: PTB, preterm birth; PSA, probabilistic sensitivity analysis; $\mathrm{HICM}$, high-intensity case management; $\mathrm{Cl}$, confidence interval (95\%).

of NICU admission, shorter NICU stays, and fewer newborns with high neonatal morbidity/mortality index scores. There is interest in a variety of other biomarker tests for PTB risk; however, uncertainties around their optimal clinical use have led to inconclusive findings with regard to costeffectiveness. ${ }^{33,34}$
The potential for cost savings from reducing the risk of PTB in the US is large. Based on our base case estimate of $\$ 863$ in cost savings per pregnant woman without clinically accepted PTB risk factors, assuming approximately 4 million births per year of which $\sim 50 \%$ occur in commercial settings, ${ }^{35}$ and further assuming at least half have no evident 
risk factors for $\mathrm{PTB},{ }^{36}$ more than $\$ 850$ million could be saved annually assuming full uptake of the risk-screen-andtreat strategy. Consistent with prior studies, healthcare expenditures in our cohort were inversely related to gestational age. ${ }^{2,3,37,38}$ Costs in our cohort tended to be higher than those in prior studies; this may be due to various methodological differences including the effects of medical care price inflation (the current study is among the most recent, using 2016 data inflation-adjusted to USD 2018) and our focus on commercially insured patients.

The PreTRM $^{\circledR}$ test is a mass-spectrometry-based serum proteomics assay, which has strengths and limitations. The IBP4 (insulin-like growth factor-binding protein 4)/SHBG (sex hormone-binding globulin) protein ratio underlying the test shows connections to pathways potentially associated with PTB. Specifically, IBP4 regulates insulin-like growth factors, which are reported to play a role in nutrient delivery to the fetus. ${ }^{39}$ IBP4 is placentally expressed with higher circulating levels reported in women with growth restricted fetuses, ${ }^{40,41}$ suggesting that its increase may signal uteroplacental insufficiency. In addition, SHBG is a placentally expressed regulator of sex steroids, ${ }^{42,43}$ suppressed by proinflammatory mediators. ${ }^{44}$ Thus, reduction in SHBG may signal an infection or inflammatory state that can lead to increased availability of free steroids involved in pregnancy, some of which promote labor. Clinically meaningful prediction of PTB may be supported by biomarkers in general pathways such as placental dysfunction and inflammation which lie downstream of individual etiologies. ${ }^{14,15}$ More generally, mass-spectrometrybased serum proteomics draws strength from minimally invasive sample collection, a precise and robust measurement technology, and use of protein analytes that are produced as functional physiological signals. Multiplexing across pathways allows proteomics to address multifactorial conditions, while being somewhat limited by lack of full genome coverage, complexity, and, potentially, cost. $^{45}$

While the focus of clinical trials of pharmacologic interventions is usually on the reduction of sPTBs, the PreTRM test has been validated to predict $\mathrm{PPTB}<37$ weeks, ${ }^{14}$ and the same biomarkers demonstrate an ability to enrich for early miPTBs across several potential medically indicated complications. ${ }^{15}$ Approximately $20-50 \%$ of PTBs are medically indicated. ${ }^{46}$ Claims data do not distinguish between spontaneous and medically indicated PTBs. Our analysis considers the average effect on amelioration of preterm birth to be independent of the reason for the preterm birth. One might consider this a limitation of the study from the standpoint of likelihood of pharmacologic interventions affecting medically indicated PTB. However, meta-analysis of vaginal progesterone treatment in high-risk women did not find evidence of differential effectiveness for amelioration of spontaneous vs medically indicated PTB. ${ }^{24}$ Furthermore, HICM studies do suggest specific benefit in reducing adverse outcomes associated with medically indicated PTB, which may in part be based on the intensive monitoring and behavioral modification aspects of such programs. ${ }^{47}$

The model was populated with usual-care PTB and cost outcomes from a population of commercially insured real-world patients, selected in order to approximate the test's intended-use population (singleton pregnancies lacking prior PTB or premature cervical shortening). We recognize that the inherent risk of PTB in the population will vary according to many genetic and environmental non-specific risk factors that are within intended use of the PreTRM test and included in the study population. We also note that the overall frequency of PTB (births $<37$ weeks) in our population of $7.0 \%$ is similar to or lower than the frequencies observed in the PreTRM clinical validation studies $(7-11 \%),{ }^{14,15}$ suggesting the test is suitable as baseline risks are aligned. Further, our sensitivity analysis considered the effect of different test performance and treatment effectiveness assumptions and indicated robustness of the base case results to such variations.

Strengths of this study include the large number of analyzed patients and generalizability to a US commercially insured population of pregnant women without clinically accepted risk factors for PTB. The distribution of births by gestational age matches prior published data. ${ }^{3,35}$ Differences in absolute frequencies may be due to our focus on commercially insured, singleton births. In general, conservative assumptions were used, including reliance on real-world data for treatment patterns and outcomes instead of assuming perfect adherence to guidelines. We assumed that multi-component treatment efficacy, as derived in our analysis from published study data, may be further attenuated by imperfect uptake and compliance. Our analysis used week-to-week estimates of cost and PTB risk, allowing us to estimate the benefits of even small-to-moderate changes in gestational age, which would not have been possible with a less granular model.

\section{Limitations}

Limitations of the study include reliance on treatment effectiveness estimates from published studies of multi-component HICM, progesterone, and novel bundled regimens in an evolving field. The interaction between effectiveness of this 
treatment and the population in which it will be used is dynamic, and to date the efficacy of progesterone has primarily been studied in women identified as high-risk using other prognostic methods, such as prior preterm birth or short cervix. ${ }^{16,24}$ While the PreTRM test would be applied to a population of otherwise low-risk women, the resulting treatment would only be targeted at those identified as higher-risk by the test, ie, a population where the treatment strategy is likely effective based on prior literature in other high-risk women. We did not model adverse events related to the risk-screening-and-test strategy; we note that safety evidence for progesterone is longstanding and reassuring. ${ }^{21,48-52}$ In light of the recent FDA proposal to withdraw the leading brand of injectable progesterone from the US market, our model focused on the vaginal formulations. ${ }^{53}$ Other treatments (eg, cerclage, antibiotics, and vitamin D) were not modelled and the conclusions from our model may not extend to their use.

The model has typical limitations common to the use of medical claims data, which lack clinical context and are subject to potential coding, billing, and recording errors as well as other inconsistencies. We did not model neonatal mortality as an isolated outcome; across the entire PTB population neonatal mortality is uncommon. ${ }^{2}$ Births $<23$ weeks' gestation, stillbirth, or abortion were also not modeled. They occurred very rarely in this sample and are not known to be affected by the treatment. Patients without health insurance or those who are covered solely under public programs (eg, Medicaid) were not part of the analyzed population; commercially insured individuals are more likely to be currently employed and tend to have many factors that put them at lower risk than the remaining population, such as lower rates of smoking or sexually transmitted diseases. While we were not able to reliably ascertain race for the patients included in this dataset, it is also likely that fewer mothers were Black, Hispanic, or of other racial and ethnic minorities, compared to national statistics. In 2018, 63\% of births to white mothers were covered by commercial insurance, versus $28 \%$ of births to Black mothers. ${ }^{4}$ Childbirth is an area of health care with particularly high disparities by race and economic status; consequently, the potential benefits of risk identification and treatment for patients underrepresented in the commercially insured population is an important area for future research.

Finally, it is important to note the limitations of our focus on direct health care cost. We did not consider quality of life (for mothers or infants) or long-term clinical sequelae, productivity, or other indirect costs, all of which may be substantially impacted by preterm birth. ${ }^{5,54-57}$ This is a conservative assumption likely to underestimate benefit of the risk-screening-and-treat strategy. Generating and incorporating appropriate data in this population would be an important task for future research.

\section{Conclusions}

In a health economic model, use of a novel blood test during the 19th-20th week of pregnancy to identify women at risk of PTB was shown to reduce health care costs and prevent delivery at early weeks of gestation in a representative population of commercially insured women in the US. These findings were consistent across a wide variety of possible scenarios in terms of test uptake, treatment adherence, treatment efficacy, and accrued costs.

\section{Acknowledgments}

We are grateful to Thomas J. Garite, MD, for gracious guidance based on his extensive clinical expertise, and to Diana Frame for writing and other editorial support for this manuscript. Partial findings from this study were previously presented at the annual meeting of the International Society for Pharmacoeconomics and Outcomes Research, held virtually May 17-20, 2021.

\section{Funding}

Study funding was provided by Sera Prognostics Inc., the maker of the PreTRM ${ }^{\circledR}$ test, to HealthCore Inc.

\section{Disclosure}

Michael Grabner, Chi Nguyen, Haechung Chung, Nilesh Gangan, and Eric Stanek are employees of HealthCore, Inc., an independent research organization that received funding from Sera Prognostics Inc. for the conduct of the study. Michael Grabner and Eric Stanek are stockholders of Anthem, Inc., which has a financial interest in Sera Prognostics. Julja Burchard and Jay Boniface are employees and stockholders of Sera Prognostics Inc. John Zupancic is a consultant to Sera Prognostics Inc. The authors report no other conflicts of interest in this work.

\section{References}

1. Barradas DT, Wasserman MP, Daniel-Robinson L, et al. Hospital utilization and costs among preterm infants by payer: Nationwide Inpatient Sample, 2009. Matern Child Health J. 2016;20(4):808-818. doi:10.1007/s10995-015-1911-y

2. Phibbs CS, Schmitt SK, Cooper M, et al. Birth hospitalization costs and days of care for mothers and neonates in California, 2009-2011. J Pediatr. 2019;204:118-125.e114. doi:10.1016/j.jpeds.2018.08.041 
3. Beam AL, Fried I, Palmer N, et al. Estimates of healthcare spending for preterm and low-birthweight infants in a commercially insured population: 2008-2016. J Perinatol. 2020;40(7):1091-1099. doi:10.1038/s41372-020-0635-Z

4. Hamilton BE, Martin JA, Osterman MJK. Births: provisional data for 2020. Vital Statistics Rapid Release; no.12. Hyattsville, MD: National Center for Health Statistics; May 2021. Available from: https://www cdc.gov/nchs/data/vsrr/vsrr012-508.pdf. Accessed June 2, 2021.

5. Waitzman NJ, Jalali A, Grosse SD. Preterm birth lifetime costs in the United States in 2016: an update. Semin Perinatol. 2021;45 (3):151390. doi:10.1016/j.semperi.2021.151390

6. Behrman RE, Butler AS. Institutes of Medicine. In: Societal Costs of Preterm Birth. Washington, DC: National Academies Press (US); 2007.

7. Petrou S, Yiu HH, Kwon J. Economic consequences of preterm birth: a systematic review of the recent literature (2009-2017). Arch Dis Child. 2019;104(5):456-465. doi:10.1136/archdischild2018-315778

8. Manuck TA, Rice MM, Bailit JL, et al. Preterm neonatal morbidity and mortality by gestational age: a contemporary cohort. Am J Obstet Gynecol. 2016;215(1):103.e1-103.e14. doi:10.1016/j. ajog.2016.01.004

9. Ananth CV, Vintzileos AM. Epidemiology of preterm birth and its clinical subtypes. J Matern Fetal Neonatal Med. 2006;19 (12):773-782. doi:10.1080/14767050600965882

10. Romero R, Dey SK, Fisher SJ. Preterm labor: One syndrome, many causes. Science. 2014;345(6198):760-765. doi:10.1126/science.1251816

11. Laughon SK, Albert PS, Leishear K, Mendola P. The NICHD Consecutive Pregnancies Study: recurrent preterm delivery by subtype. Am J Obstet Gynecol. 2014;210(2):131.e1-131.e8. doi:10.1016/j.ajog.2013.09.014

12. Esplin MS, Elovitz MA, Iams JD, et al. Predictive accuracy of serial transvaginal cervical lengths and quantitative vaginal fetal fibronectin levels for spontaneous preterm birth among nulliparous women. JAMA. 2017;317(10):1047-1056. doi:10.1001/jama.2017.1373

13. Iams JD, Solomon CG. Clinical practice. Prevention of preterm parturition. $N$ Engl J Med. 2014;370(3):254-261. doi:10.1056/ NEJMcp 1103640

14. Saade GR, Boggess KA, Sullivan SA, et al. Development and validation of a spontaneous preterm delivery predictor in asymptomatic women. Am J Obstet Gynecol. 2016;214(5):633.e1-633.e24. doi:10.1016/j.ajog.2016.02.001

15. Markenson GR, Saade GR, Laurent LC, et al. Performance of a proteomic preterm delivery predictor in a large independent prospective cohort. Am J Obstet Gynecol MFM. 2020;2(3):100140. doi:10.1016/j.ajogmf.2020.100140

16. Society for Maternal-Fetal Medicine Publications Committee. Progesterone and preterm birth prevention: Translating clinical trials data into clinical practice. Am J Obstet Gynecol. 2012;206 (5):376-386. doi:10.1016/j.ajog.2012.03.010

17. Hillemeier MM, Domino ME, Wells R, et al. Effects of maternity care coordination on pregnancy outcomes: Propensity-weighted analyses. Matern Child Health J. 2015;19(1):121-127. doi:10.1007/ s10995-014-1502-3

18. Newman RB, Sullivan SA, Menard MK, et al. South Carolina Partners for Preterm Birth Prevention: a regional perinatal initiative for the reduction of premature birth in a Medicaid population. Am J Obstet Gynecol. 2008;199(4):393.e1-393.e8. doi:10.1016/j.ajog.2008.07.047

19. Caughey AB, Zupancic JA, Greenberg JM, Garfield SS, Thung SF, Iams JD. Clinical and cost impact analysis of a novel prognostic test for early detection of preterm birth. AJP Rep. 2016;6(4):e407-e416. doi: $10.1055 / \mathrm{s}-0036-1593866$

20. Siebert U, Alagoz O, Bayoumi AM, et al. State-transition modeling: a report of the ISPOR-SMDM Modeling Good Research Practices Task Force-3. Value Health. 2012;15(6):812-820. doi:10.1016/j. jval.2012.06.014
21. Meis PJ, Klebanoff M, Thom E, et al. Prevention of recurrent preterm delivery by 17 alpha-hydroxyprogesterone caproate. $N$ Engl J Med. 2003;348(24):2379-2385. doi:10.1056/NEJMoa035140

22. Manuck TA, Henry E, Gibson J, et al. Pregnancy outcomes in a recurrent preterm birth prevention clinic. Am J Obstet Gynecol. 2011;204(4):320.e1-320.e6. doi:10.1016/j.ajog.2011.01.011

23. Grobman WA, Thom EA, Spong CY, et al. 17 alpha-hydroxyprogesterone caproate to prevent prematurity in nulliparas with cervical length less than $30 \mathrm{~mm}$. Am J Obstet Gynecol. 2012;207(5):390.e1-390.e8. doi:10.1016/j.ajog.2012.09.013

24. Romero R, Conde-Agudelo A, Da Fonseca E, et al. Vaginal progesterone for preventing preterm birth and adverse perinatal outcomes in singleton gestations with a short cervix: a meta-analysis of individual patient data. Am J Obstet Gynecol. 2018;218(2):161-180. doi:10.1016/j.ajog.2017.11.576

25. Blackwell SC, Gyamfi-Bannerman C, Biggio JR Jr., et al. 17-OHPC to prevent recurrent preterm birth in singleton gestations (PROLONG Study): a multicenter, international, randomized double-blind trial. Am J Perinatol. 2020;37(2):127-136. doi:10.1055/s-0039-3400227

26. Branch DW, Esplin MS, Porter F, et al. Prediction and Prevention of Preterm Birth: A prospective, randomized intervention trial. Society for Reproductive Investigation; 2020:abstract LBA-003.

27. Branch DW, VanBuren JM, Porter TF, et al. Prediction and Prevention of Preterm Birth: A prospective, randomized intervention trial. Am J Perinatol. Epub 2021 Aug 16. doi:10.1055/s-00411732339

28. ClinicalTrials.gov. National Library of Medicine. Prematurity risk assessment combined with clinical interventions for improving neonatal outcomes (PRIME). Identifier NCT04301518; March 2020. Available from: https://www.clinicaltrials.gov/ct2/show/ NCT04301518. Accessed June 2, 2021.

29. ClinicalTrials.gov. National Library of Medicine. Serum assessment of preterm birth outcomes compared to historical controls: AVERT PRETERM TRIAL. Identifier NCT03151330; May 2017. Available from: https://www.clinicaltrials.gov/ct2/show/NCT03151330. Accessed June 2, 2021.

30. Bureau of Labor Statistics. United States department of labor; 2020. Available from: http://data.bls.gov/cgi-bin/srgateseries_id= CUUR0000SAM, (Consumer Price Index medical care component). Accessed June 2, 2021.

31. Hassan SS, Romero R, Vidyadhari D, et al. Vaginal progesterone reduces the rate of preterm birth in women with a sonographic short cervix: a multicenter, randomized, double-blind, placebo-controlled trial. Ultrasound Obstet Gynecol. 2011;38(1):18-31. doi:10.1002/ uog.9017

32. Office of Disease Prevention and Health Promotion, US Department of Health And Human Services. Healthy People 2020: Leading Health Indicators. Available from: https://www.healthypeople.gov/ 2020/Leading-Health-Indicators. Accessed June 2, 2021.

33. Glover AV, Manuck TA. Screening for spontaneous preterm birth and resultant therapies to reduce neonatal morbidity and mortality: A review. Semin Fetal Neonatal Med. 2018;23(2):126-132. doi:10.1016/j.siny.2017.11.007

34. Varley-Campbell J, Mújica-Mota R, Coelho H, et al. Three biomarker tests to help diagnose preterm labour: a systematic review and economic evaluation. Health Technol Assess. 2019;23(13):1-226. doi:10.3310/hta23130

35. Martin JA, Hamilton BE, Osterman MJK, Driscoll AK. Births: final data for 2018. Natl Vital Stat Rep. 2019;68(13):1-47.

36. Boniface JJ, Burchard J, Saade GR. Effects of selective exclusion of patients on preterm birth test performance. Obstet Gynecol. 2019;134 (6):1333-1338. doi:10.1097/AOG.0000000000003511

37. Pizzi LT, Seligman NS, Baxter JK, Jutkowitz E, Berghella V. Cost and cost effectiveness of vaginal progesterone gel in reducing preterm birth: an economic analysis of the PREGNANT trial. Pharmacoeconomics. 2014;32(5):467-478. doi:10.1007/s40273-014-0133-2 
38. Truven Health Analytics. The cost of having a baby in the United States. In: Truven Health Analytics MarketScan ${ }^{\circledR}$ Study. 2013. Available from: https://www.nationalpartnership.org/our-work/ resources/health-care/maternity/archive/the-cost-of-having-a-baby-inthe-us.pdf. Accessed June 2, 2021.

39. Forbes K, Westwood M. Maternal growth factor regulation of human placental development and fetal growth. J Endocrinol. 2010;207 (1):1-16. doi:10.1677/JOE-10-0174

40. Crosley EJ, Dunk CE, Beristain AG, Christians JK. IGFBP-4 and -5 are expressed in first-trimester villi and differentially regulate the migration of HTR-8/SVneo cells. Reprod Biol Endocrinol. 2014;12 (1):123. doi:10.1186/1477-7827-12-123

41. Qiu Q, Bell M, Lu X, et al. Significance of IGFBP-4 in the development of fetal growth restriction. J Clin Endocrinol Metab. 2012;97 (8):E1429-1439. doi:10.1210/jc.2011-2511

42. Larrea F, Díaz L, Cariño C, et al. Evidence that human placenta is a site of sex hormone-binding globulin gene expression. J Steroid Biochem Mol Biol. 1993;46(4):497-505. doi:10.1016/0960-0760(93) 90104-5

43. Hammond GL. Diverse roles for sex hormone-binding globulin in reproduction. Biol Reprod. 2011;85(3):431-441. doi:10.1095/ biolreprod.111.092593

44. Simó R, Sáez-López C, Barbosa-Desongles A, Hernández C, Selva DM. Novel insights in SHBG regulation and clinical implications. Trends Endocrinol Metab. 2015;26(7):376-383. doi:10.1016/j.tem.2015.05.001

45. Bensimon A, Heck AJ, Aebersold R. Mass spectrometry-based proteomics and network biology. Annu Rev Biochem. 2012;81 (1):379-405. doi:10.1146/annurev-biochem-072909-100424

46. Stout MJ, Busam R, Macones GA, Tuuli MG. Spontaneous and indicated preterm birth subtypes: interobserver agreement and accuracy of classification. Am J Obstet Gynecol. 2014;211(5):530.e531530.e534. doi:10.1016/j.ajog.2014.05.023

47. Barton JR, Istwan NB, Rhea D, Collins A, Stanziano GJ. Costsavings analysis of an outpatient management program for women with pregnancy-related hypertensive conditions. Dis Manag. 2006;9 (4):236-241. doi:10.1089/dis.2006.9.236

48. Seegmiller RE, Nelson GW, Johnson CK. Evaluation of the teratogenic potential of delalutin (17 alpha-hydroxyprogesterone caproate) in mice. Teratology. 1983;28(2):201-208. doi:10.1002/tera.1420280208
49. Christian MS, Brent RL, Calda P. Embryo-fetal toxicity signals for 17alpha-hydroxyprogesterone caproate in high-risk pregnancies: a review of the non-clinical literature for embryo-fetal toxicity with progestins. J Matern Fetal Neonatal Med. 2007;20(2):89-112. doi:10.1080/14767050601178758

50. McNamara HC, Wood R, Chalmers J, et al. STOPPIT Baby Follow-up Study: the effect of prophylactic progesterone in twin pregnancy on childhood outcome. PLoS One. 2015;10(4):e0122341. doi:10.1371/journal.pone.0122341

51. Norman JE, Marlow N, Messow CM, et al. Vaginal progesterone prophylaxis for preterm birth (the OPPTIMUM Study): a multicentre, randomised, double-blind trial. Lancet. 2016;387(10033):2106-2116. doi:10.1016/S0140-6736(16)00350-0

52. Northen AT, Norman GS, Anderson K, et al. Follow-up of children exposed in utero to 17 alpha-hydroxyprogesterone caproate compared with placebo. Obstet Gynecol. 2007;110(4):865-872. doi:10.1097/01. AOG.0000281348.51499.bc

53. Food and Drug Administration. CDER proposes withdrawal of approval for Makena; 2020. Available from: https://www.fda.gov/ drugs/drug-safety-and-availability/cder-proposes-withdrawalapproval-makena. Accessed June 2, 2021.

54. Crump C, Sundquist J, Howell EA, McLaughlin MA, Stroustrup A, Sundquist K. Pre-term delivery and risk of ischemic heart disease in women. J Am Coll Cardiol. 2020;76(1):57-67. doi:10.1016/j. jacc.2020.04.072

55. Crump C. Adult mortality after preterm birth-time to translate findings into clinical practice. JAMA Netw Open. 2021;4(1):e2033361. doi:10.1001/jamanetworkopen.2020.33361

56. Raju TNK, Pemberton VL, Saigal S, Blaisdell CJ, Moxey-Mims M, Buist S. Long-term healthcare outcomes of preterm birth: an executive summary of a conference sponsored by the National Institutes of Health. J Pediatr. 2017;181:309-318.e1. doi:10.1016/j.jpeds.2016.10.015

57. Wu P, Gulati M, Kwok CS, et al. Preterm delivery and future risk of maternal cardiovascular disease: a systematic review and meta-analysis. J Am Heart Assoc. 2018;7(2):e007809. doi:10.1161/JAHA.117.007809
ClinicoEconomics and Outcomes Research

\section{Publish your work in this journal}

ClinicoEconomics and Outcomes Research is an international, peerreviewed open-access journal focusing on Health Technology Assessment, Pharmacoeconomics and Outcomes Research in the areas of diagnosis, medical devices, and clinical, surgical and pharmacological intervention. The economic impact of health policy and health systems organization also constitute important areas of coverage. The manuscript management system is completely online and includes a very quick and fair peer-review system, which is all easy to use. Visit http://www.dovepress.com/testimonials.php to read real quotes from published authors.

Submit your manuscript here: https://www.dovepress.com/clinicoeconomics-and-outcomes-research-journal 